\title{
História das práticas de avaliação e ensino na USP: marcas da missão francesa na educação universitária paulista
}

The history of evaluation and teaching practices at USP: marks of the French mission in the higher education in São Paulo

Historia de las prácticas de evaluación y enseñanza en la USP: marcas de la misión francesa en la educación universitaria en Sao Paulo

\author{
Katiene Nogueira da Silva \\ Universidade de São Paulo (Brasil) \\ http://lattes.cnpq.br/8523522666926651 \\ https://orcid.org/0000-0002-1280-3041 \\ katiene@usp.br \\ Denice Barbara Catani \\ Universidade de São Paulo (Brasil) \\ http://lattes.cnpq.br/3792758221330745 \\ https://orcid.org/0000-0001-6019-8969 \\ dbcat@usp.br
}

\section{Resumo}

O presente artigo busca contribuir para a produção de conhecimento sobre a cultura universitária brasileira a partir do estudo de práticas de avaliação das aprendizagens, tomando como fontes para a pesquisa documentos da Universidade de São Paulo, entre eles os relatórios confidenciais da missão francesa que ajudou a fundar a universidade. O que aqui se apresenta origina-se numa pesquisa que teve por objetivo recuperar, conhecer e analisar a proposição de práticas de avaliação e de ensino que estiveram vigentes na Universidade de São Paulo desde a sua criação, 1934 até 1968, ano da Reforma Universitária.

Palavras-chave: Cultura universitária. USP. Práticas de avaliação e ensino. 


\begin{abstract}
This article seeks to contribute to the production of knowledge about Brazilian university culture based on the study of learning assessment practices, taking as sources for research documents from the University of São Paulo, among them the confidential reports of the French mission that helped to found the university. What is presented here is originated from a research that aimed to recover, know and analyze the proposal of evaluation and teaching practices that were in force at the University of São Paulo since its creation, 1934 to 1968, the year of the University Reform.
\end{abstract}

Keywords: University culture. USP. Assessment and teaching practices.

\title{
Resumen
}

Este artículo busca contribuir a la producción de conocimiento sobre la cultura universitaria brasileña a partir del estudio de las prácticas de evaluación del aprendizaje, tomando como fuentes de investigación documentos de la Universidad de São Paulo, entre ellos los informes confidenciales de la misión francesa que ayudó a fundar la universidad. Lo que se presenta aquí se origina en una investigación que tuvo como objetivo recuperar, conocer y analizar la propuesta de evaluación y prácticas docentes vigentes en la Universidad de São Paulo desde su creación, 1934 hasta 1968, año de la Reforma Universitaria.

Palabras clave: Cultura universitaria. USP. Evaluación y prácticas docentes. 


\section{Introdução}

$\mathrm{O}$ que aqui se apresenta origina-se numa pesquisa que teve por objetivo recuperar, conhecer e analisar a proposição de práticas de avaliação e de ensino que estiveram vigentes na Universidade de São Paulo desde a sua criação, $1934^{1}$ até 1968, ano da Reforma Universitária. A investigação das práticas de avaliação e de ensino nos permite compreender os elementos que mobilizam as classificações que os professores produzem em seu cotidiano e os julgamentos que constroem sobre os seus alunos ou, nas palavras de Pierre Bourdieu e Monique de Saint-Martin (1999), "as categorias do juízo professoral". A esse propósito, podemos pensar, por exemplo, nas expectativas que tinham os professores franceses com relação ao desempenho de seus alunos brasileiros na Universidade de São Paulo, conforme apresentaremos adiante. Acerca da concepção de "práticas", vale a pena recuperarmos ainda as palavras destes autores: "(...) podese admitir que a prática implica sempre uma operação de conhecimento, isto é, uma operação mais ou menos complexa de classificação, que nada tem em comum com um registro passivo, sem no entanto fazer disto uma construção puramente intelectual; o conhecimento prático é uma operação prática de construção que aciona, por referência a funções práticas, sistemas de classificação (taxonomias) que organizam a percepção e a apreciação, e estruturam a prática" (op. cit., p. 187). Nesta perspectiva, os esquemas de percepção, de apreciação e de ação são adquiridos pela prática e "funcionam como operadores práticos através dos quais as estruturas objetivas das quais eles são produto tendem a se reproduzir nas práticas" (op. cit., p. 187). Os trabalhos de Pierre Bourdieu e colaboradores sustentam a análise. Beatriz Fétizon e Irene Cardoso fornecem importantes elementos sobre a história da USP. Claude Lévi-Strauss, Roger Bastide, entre outros, permitem compreender a perspectiva dos integrantes da missão ao fornecerem depoimentos acerca do trabalho docente na universidade, de sua percepção e avaliação sobre os alunos.

Ao estudar o projeto de criação da Universidade de São Paulo, Irene Cardoso (1982) trata de uma questão pertinente à política empreendida por um grupo de jornalistas, intelectuais e políticos nos anos de 1930: a formação das "elites" que seriam capazes de desenvolver intelectualmente os projetos da oligarquia que estava em crise. Trazendo consigo a "missão superior de formação da nacionalidade" e herdeiros das "melhores tradições cívicas e intelectuais", o "grupo do Estado" - porta-voz do jornal O Estado de São Paulo - liderado por Julio de Mesquita Filho, se pensava como capaz de conduzir o "reencontro do Brasil com o seu destino de grandeza Paulista". Com o objetivo de garantir sua posição de independência diante das ações partidárias, as ações do "grupo do Estado" seriam voltadas para a criação de uma instituição na qual deveriam imperar os princípios do "bandeirismo ilustrado", sendo a Universidade o centro irradiador do mesmo. A pedido de Julio de Mesquita Filho, Fernando de Azevedo realizou o "Inquérito sobre a Instrução Pública" (CARDOSO, 1982). O referido jornal defendia como princípio uma espécie de "liberalismo orientado", ou seja, que o sistema escolar produzisse uma "elite norteadora" e um ensino "livre", acima dos interesses partidários. Neste contexto ganharia força a ideia da Universidade como formadora de elites intelectuais e políticas. Segundo a autora, "contra uma possível identificação destas posições com uma concepção aristocrática da sociedade, o que o Inquérito renegou, [Fernando de Azevedo] lembra não haver conflito entre o ideal da formação das elites e os ideais democráticos, pois educação popular e preparo das elites seriam duas faces de um único problema, o da formação da cultura nacional" (op. cit., p. 30). O Inquérito propõe, nas palavras da autora, um "mecanismo de circulação das elites" que solucionaria a oposição entre elite e massa. É dito no documento que “à medida que a educação for estendendo a sua influência, despertadora de vocações, vai penetrando até as camadas mais obscuras, para aí, entre os próprios operários, descobrir o

\footnotetext{
${ }^{1}$ O projeto "História das Práticas de Avaliação na Universidade de São Paulo (Curso de Pedagogia - 1938 até os dias atuais)" foi desenvolvido por Katiene Nogueira da Silva no âmbito do pós-doutorado entre 2012 e 2013, supervisionado por Denice Barbara Catani e contou com o financiamento da FAPESP.
} 
grande homem, o cidadão útil, que o estado tem o dever de atrair, submetendo a uma prova constante as ideias e os homens, para os elevar e selecionar segundo o seu valor ou a sua incapacidade" (op. cit., p. 31). Assim, caberia à Universidade a tarefa de "divulgação" das ciências, colocando-as ao "alcance do povo" mediante um sistema que contaria com ensino, pesquisa e extensão universitária e chegaria até as camadas populares. A partir de tais pressupostos o Inquérito preparado por Fernando de Azevedo postulava que a Universidade seria o "instrumento mais eficaz" na "obra de coesão nacional". No discurso de Azevedo, a mudança demonstrada de um liberalismo clássico para um "Estado programador" teria ocorrido por influência da Revolução de 30. (CARDOSO, 1982). Nesse sentido, o Estado "programador" poderia operar também na seleção e na "elevação" dos mais capazes. Caberia ao ensino superior realizar a formação das elites, garantindo às massas o acesso ao ensino primário. Entre as massas e as elites estava a classe média, para a qual era destinado o ensino secundário, e que seria a "divulgadora da cultura universitária". Importantes trabalhos sobre a universidade brasileira já foram realizados, dentre eles, por exemplo, Cunha $(1980,1983,1988)$, Fávero (2000, 2010), Bontempi Júnior (2008).

O presente artigo busca contribuir para a produção de conhecimento sobre a cultura universitária brasileira a partir do estudo de práticas de avaliação das aprendizagens, tomando como fontes para a pesquisa documentos da Universidade de São Paulo e documentos produzidos por professores que integraram a missão francesa que ajudou a fundar a universidade, entre eles os relatórios confidenciais da missão francesa. Trata-se de um conjunto de correspondências, manuscritas ou datilografadas, que circulavam entre o Brasil e a França dando notícias sobre o trabalho dos professores franceses e o funcionamento da recém-fundada universidade.

\section{A missão francesa e seus herdeiros intelectuais}

Foi para pôr a juventude paulista no nível da cultura europeia que aqueles aristocratas burgueses decidiram criar a universidade. Mas, por uma espécie de paradoxo, os estudantes vinham de classes modestas, porque havia um grande desnível entre a elite e a massa da sociedade, que continuava pobre e de espírito provinciano. Os estudantes, frequentemente homens e mulheres já empenhados numa vida profissional, desconfiavam dos grandes burgueses que haviam fundado a universidade. $\mathrm{E}$ até nós nos encontrávamos entre dois campos. Ao mesmo tempo que nos consideravam pessoas de valor, os estudantes às vezes nos encaravam como servidores da classe dominante.

Claude Lévi-Strauss, em entrevista concedida à Didier Eribon

A Universidade de São Paulo, em sua criação, pretendia realizar a formação intelectual do país, consoante à ideia segundo a qual o Estado de São Paulo tomaria para si essa tarefa. A influência europeia e a ênfase francesa marcaram a origem da instituição: de um lado estava o "saber desinteressado", os conhecimentos que enriqueceriam e desenvolveriam o espírito e, de outro lado, estavam os "saberes utilitários", os conhecimentos que seriam úteis à vida prática (FÉTIZON, 1986). Em um primeiro momento, durante a criação da USP, houve a tentativa por 
parte do Estado de implantar o modelo originário - europeu - em sua forma mais pura. Segundo Beatriz Fétizon (1986), a partir de 1938 iniciou-se a primeira acomodação do modelo inicial da Faculdade de Filosofia, Ciências e Letras (FFCL), "tornada uma escola de formação profissional pela criação de sua quarta seção (Pedagogia)" (op. cit., p. 399). Marcada pela meritocracia, a FFCL era voltada para a universalidade do saber de alto nível. A contratação de professores estrangeiros marcou a primeira geração de intelectuais, docentes e pesquisadores formados nos procedimentos de um modelo de investigação rigorosa. A entrada dos estudos de educação para a FFCL, como uma quarta seção - a de Pedagogia - em 1938, consagrou o abandono do modelo originário puro. Neste sentido, a seção de Pedagogia marcou a Faculdade de Filosofia, Ciências e Letras de uma forma muito particular, pois estava em uma instituição baseada no rigor dos procedimentos de pesquisa e no saber de caráter desinteressado, mas precisava conduzir ao mesmo tempo uma formação voltada para o trabalho e para a prática. Os primeiros professores do Instituto de Educação eram os antigos professores do Curso Normal, que foram elevados com o Curso de Aperfeiçoamento ao nível superior, fazendo com que a USP tivesse professores catedráticos que não tinham curso superior (FÉTIZON, 1986).

O Instituto de Educação, antigo "Instituto Caetano de Campos", criado para formar professores em nível superior junto à Escola Normal da Capital, foi fundado em 1933 e logo em seguida incorporado à Universidade de São Paulo, em 1934. Em 1938 foi transformado na Seção de Pedagogia da Faculdade de Filosofia, Ciências e Letras e, posteriormente, no Departamento de Educação. O decreto n 6.283 de 25 de janeiro de 1934, que "Crea a Universidade de São Paulo e dá outras providências", determinou o seguinte em seu Capítulo I, intitulado "Do Instituto de Educação: Art. 50 - O Instituto de Educação, antigo Instituto "Caetano de Campos" participará da Universidade exclusivamente pela sua Escola de Professores, ficando-lhe porém, subordinados administrativa e tecnicamente, como institutos anexos, o Curso Complementar, a Escola Secundária, a Escola Primária e o Jardim da Infância, destinados a experimentação, demonstração e prática do ensino e ao estágio profissional dos alunos da Escola de Professores". Além de formar professores conforme a necessidade imposta pelo sistema educacional do Estado, o Instituto também organizou-se para ser uma "alta escola de administração escolar", a primeira que se instalou no país, e para colaborar com a Faculdade de Filosofia, Ciências e Letras (FFCL) na formação do professor secundário. O Instituto de Educação possuía vários cursos universitários, com cerca de 45 alunos por classe. Ele foi criado não apenas para ministrar cultura geral ao professor, mas também para a sua preparação técnica, por meio de estudos das bases científicas da profissão e aquisição de técnicas de trabalho, pelo estágio profissional nas escolas anexas, para a demonstração, observação e prática de ensino (Decreto $n^{\circ} 7.067$, de 6 de abril de 1935). À FFCL, que abrigou entre outros o Curso de Pedagogia, foi atribuído o papel de ser o "espírito" da Universidade, nas palavras de Arbousse Bastide, que foi o chefe da missão francesa e tinha como prerrogativa dirigir e orientar o ensino com os "melhores critérios didáticos" para cumprir o objetivo de formação da elite universitária. Acerca da contratação dos professores franceses, vale a pena lembrarmos o trecho do livro Tristes Trópicos (1996), no qual Claude Lévi-Strauss publicou suas memórias acerca da época em que foi convidado a participar da missão francesa. Em 1934, Lévi-Strauss conta que recebeu um telefonema do então diretor da Escola Normal Superior, Célestin Bouglé, que lhe fez a seguinte pergunta: "Você continua com vontade de fazer etnografia?'. 'Sem dúvida!' 'Então, apresente sua candidatura para professor de sociologia da Universidade de São Paulo. Os arredores estão repletos de índios, a quem você dedicará os seus fins de semana.' " (op. cit., p. 45)

Uma vez contratados, os professores deveriam seguir as normas que regulavam a recémfundada instituição. Para o que aqui nos interessa, ou seja a história das práticas de avaliação na universidade, vale a pena observar as disposições legais que regularam em momentos diversos a vida escolar na instituição. No decreto $n^{\circ} 39$ de 3 de setembro de 1934, o primeiro 
documento que aprova os estatutos da Universidade de São Paulo, em seu Capítulo III, intitulado "Dos exames e promoções", consta o seguinte:

Art. 124 - A verificação de habilitação nos cursos universitários, seja para a expedição de certificados e diplomas, seja para a promoção aos períodos letivos seguintes, será feita pelas provas e médias abaixo e numeradas, em épocas e com processos discriminados nos regulamentos dos institutos universitários, respeitadas as leis vigentes:

a) provas parciais;

b) provas finais;

c) médias de trabalhos práticos ou de outros exercícios escolares.

Art. 125 - As provas finais referidas no artigo anterior serão julgadas por comissões examinadoras, das quais farão parte, obrigatoriamente os professores e docentes que houverem realizado os respectivos cursos.

Art. 126 - As taxas de exame serão fixadas em tabelas anexas aos regulamentos dos institutos universitários, onde se discriminará a gratificação que deva ser concedida aos membros das comissões examinadoras.

O Estatuto da Universidade de São Paulo (Ante-projeto aprovado pelo Conselho Universitário em sessão de 16 de janeiro de 1939), no capítulo referente aos exames e promoções, reproduz o disposto no Estatuto anterior. Acresce, entretanto, algumas indicações de caráter disciplinar. Observe-se, por exemplo:

Art. 160 - Serão eliminados os alunos dos institutos universitários:

b) quando perderem o ano por faltas ou reprovação em 2 anos sucessivos; (...)

a) quando reincidirem em fraudes na realização das provas e trabalhos escolares referidos no artigo 148. (p. 48)

Na década de 1960, os estatutos da universidade sofrem algumas alterações. Em 1965, com a Portaria GR $n^{\circ} 174$, de 21 de julho de 1965, que altera dispositivos dos Estatutos da Universidade de São Paulo e dá outras providências há a seguinte mudança com relação à promoção dos alunos: "Artigo 125 - Será recusada nova matrícula ao aluno reprovado mais de uma vez em qualquer série ou conjunto de disciplinas. Parágrafo único - Para os efeitos deste artigo, o regulamento de cada estabelecimento disporá sobre o entendimento a ser dado a conjunto de disciplinas" (p. 7).

Nas décadas de 1930 e de 1940, as políticas sociais criaram oportunidades que permitiram que uma parcela da classe média chegasse à Universidade, trazendo para esta instituição uma clientela cada vez mais diversificada no que tange tanto à sua origem sócio econômica quanto ao capital cultural apresentado. Nas palavras de Alfredo Bosi, escritas no prefácio do livro de Irene Cardoso (1982), tratava-se de uma clientela "para a qual o estudo não era só o pão já assado e partido pelo saber acadêmico, mas também um fermento que poderia levedar as novas massas. Ao longo do processo, os melhores professores passaram de "enfants gâtés' a 'enfants terribles"' (op. cit., p. 16). As expectativas docentes foram confrontadas com o comportamento discente e o modo de se relacionar com o conhecimento neste nível de ensino. Em relação às representações de aprendizagem que marcaram as práticas de avaliação no curso de Pedagogia, que depois foi abrigado pela Faculdade de Educação da USP no ano de criação desta, em 1969, e que funcionou efetivamente a partir de 1970, o modelo francês trouxe muitas influências. Pode-se observar o fato, por exemplo, atentando para o papel que a retórica e a dissertação desempenharam inicialmente nos cursos. Se a experiência pessoal dos professores 
e a sua subjetividade levam à formulação de parâmetros quantitativos, o juízo acerca da qualidade do trabalho produzido pelos alunos pode ser subjetivo e baseado na experiência e nos conhecimentos dos docentes. As experiências que os professores tiveram no momento em que eram alunos produzem representações que influenciam a prática educativa, a maneira de lecionar e o modo de avaliar (PERRENOUD, 1993). Segundo Florestan Fernandes (1984), os primeiros alunos da Universidade de São Paulo eram "ingênuos e puros", e sua "rusticidade" deve ter assustado os primeiros professores franceses que, por sua vez, "enfrentavam" os seus alunos como "iguais". Acerca do processo de avaliação vale a pena transcrevermos o trecho no qual Fernandes relata o primeiro trabalho que fez para a disciplina do professor Roger Bastide: “(...) ele recriminava-me porque não desenvolvera uma dissertação, mas uma 'reportagem'. Não obstante, o mesmo Roger Bastide, mais tarde, em 1943, deu dez e elogiou um trabalho sobre 'o primitivo, o louco e a criança' no qual caí de paus e pedras sobre a proposição de tal tema... Ele mesmo me convidou para ir a sua casa, em 1942, para discutir uma pesquisa sobre folclore, que eu fizera no ano de 1941. Em suma, o aluno era levado a sério como pessoa, era tratado como ser maduro (um aprendiz não é o outro do mestre?), tutelado e distinguido se o merecesse e, principalmente, não havia limites em sua liberdade, embora fosse responsável pelo uso que dela fizesse e acabasse pagando duramente o preço dessa liberdade" (op. cit. apud FÉTIZON, 1986, p. 474). O relato de Fernandes evidencia a influência que o modelo francês trouxe para as ideias de aprendizagem que circularam na USP, especialmente em seu momento de criação. Para além do choque ocorrido entre as representações de aprendizagem e de estudo trazidas por esses professores e a clientela escolar encontrada, como observou Fernandes, pensamos a propósito das representações de excelência do desempenho dos alunos. De acordo com Lévi-Strauss (2005), a propósito dos universitários paulistas, "os estudantes tinham um colossal apetite de saber. Aliás, num certo sentido, eles sabiam mais do que nós, porque, como autodidatas, eles tinham lido tudo, devorado tudo, mas em obras de segunda ou terceira mão. Nossa tarefa era menos ensinar-lhes as coisas que eles ignoravam do que dar-lhes uma disciplina intelectual" (op. cit., p. 34). A missão francesa e a geração dos anos 40 preparou a USP dos anos 60, ao formar grande parte do corpo docente que passou a lecionar nesta universidade, imprimindo marcas bem visíveis na formação acadêmica daquelas pessoas.

\section{As práticas de ensino, a avaliação na USP e as marcas da tradição francesa}

No primeiro período de funcionamento da Universidade, é importante chamar a atenção para o choque de representações que ocorreu entre os professores franceses e os estudantes brasileiros. Pela tese de doutorado de Beatriz Fétizon (1986) conhecemos o relato de Florestan Fernandes a propósito da impressão que teve para Arbousse Bastide saber que seus alunos liam no bonde: "Quando chegou a minha vez, relatei constrangido o que fazia. Ao mencionar Durkheim (...) esclareci: 'leio no bonde'. Foi um escândalo. (...) Se ele tivesse perguntado, explicaria que lia em uma viagem que começava na Praça da Sé e terminava na Penha, em horas que permitiam grande sossego no bonde... Existiam outros tipos de rusticidade e de tortura dos refinamentos da alta cultura. Inclusive havia um patamar de ignorância que brigava com $o$ padrão sofisticado e complexo de aprendizagem." (op. cit., 472-473) Ao consultar os relatórios confidenciais da missão francesa, foi possível conhecer as apreciações desses professores acerca dos alunos, considerados "inteligentes, mas mais superficiais do que instruídos", dando a impressão estes fossem talvez mais ilustrados do que eruditos. No documento intitulado Notes sur une mission à la Faculté nouvelle de São Paulo (juin - décembre 1934), encontramos o seguinte : «Pela diversidade de suas idades e de suas situações, eles constituíam uma amostra da sociedade paulista : o ensino dado pela faculdade não tinha muita repercussão. Inteligentes, mais superficiais do que instruídos ; formação quase nula ; um trabalho sério ; constante » (página 1 - tradução nossa). O relato manuscrito no documento francês vai ao encontro do que 
diz Florestan Fernandes acerca dos alunos e da primeira da Faculdade de Filosofia, Ciências e Letras da USP, que eram, em suas palavras "na maioria das classes médias, muitos com tradição cultural, graças ao nível social de suas famílias, mas a maior parte toscos, aprendizes ou oficiantes da primeira missa. No entanto, o saber queimava em seu ser como ferro em brasa." (FERNANDES, F. apud FÉTIZON, B., 1986, p. 472) Certa fragilidade observada na formação dos jovens brasileiros e modos de estudos considerados um tanto exóticos pelos franceses, como a situação relatada, preocupavam seus professores pois, além de ensinar-lhes os conteúdos ministrados nos cursos, fazia parte da missão fazer com que a tradição francesa relativa à maneira pela qual as pessoas produzem, divulgam e lidam com o conhecimento criasse raízes e proliferasse na Universidade que acabava de ser criada.

No documento intitulado Note pour monsieur Marx, o professor Braudel, ao expor as condições do ensino em São Paulo, sugere a criação de "três ou quatro bolsas de estudo" para os estudantes trabalharem sob a orientação dos professores e darem continuidade às tradições francesas. Jean Marx era o diretor do Service des Oeuvres Françaises à l'Étranger, órgão do Ministère des Affaires Etrangéres. Com frequência os pedidos dos professores da missão eram endereçados a ele, como o seguinte: «Senhor Braudel sugere a criação de 3 ou 4 bolsas de estudos para os estudantes da Universidade de São Paulo. As primeiras devendo ser dadas aos excelentes orientandos que trabalharam sob a direção de nosssos professores. Quando um movimento de nacionalistas distanciar os professores estrangeiros, esses antigos bolsistas continuarão as tradições francesas » (páginas 2-3 - tradução nossa, grifos nossos). A respeito de tais tradições, cabe lembrar o relato de Claude Lévi-Strauss, no livro Tristes Trópicos (1996), ao rememorar a sua vida acadêmica na Sorbonne. No momento em que se preparava para a licenciatura em filosofia, o autor nos dá pistas da importância que a dialética teve na sua própria formação e a influência que teria na formação das primeiras turmas de filosofia da USP. Sobre o seu aprendizado na faculdade francesa, ele diz:

ali comecei a aprender que todo problema, grave ou fútil, pode ser liquidado pela aplicação de um método, sempre idêntico, que consiste em contrapor duas visões tradicionais da questão; em introduzir a primeira pelas justificações do sentido comum, depois, em destruí-las por meio da segunda; por último, opô-las mutuamente graças a uma terceira que revela o caráter também parcial das outras duas, reduzidas pelos artifícios do vocabulário aos aspectos complementares de uma mesma realidade: forma e fundo, continente e conteúdo, ser e parecer, contínuo e descontínuo, essência e existência etc. Tais exercícios logo $\underline{\text { se tornam verbais, baseados numa arte do trocadilho que ocupa o lugar }}$ da reflexão; as assonâncias entre os termos, as homofonias e as ambiguidades fornecem progressivamente a matéria dessas piruetas especulativas por cuja engenhosidade se reconhecem os bons trabalhos filosóficos. Cinco anos de Sorbonne reduziram-se ao aprendizado dessa ginástica cujos perigos, todavia, são óbvios. Primeiramente, porque a mola de tais acrobacias é tão simples que não há problema que não possa ser tratado dessa maneira. Para preparar o concurso e essa prova suprema, a aula (que consiste, após algumas horas de preparação, em discorrer sobre um tema sorteado), meus companheiros e eu propúnhamos os assuntos mais extravagantes. Eu me gabava de elaborar em dez minutos uma conferência de uma hora, com sólido arcabouço dialético, sobre a superioridade respectiva dos ônibus e dos bondes. $\mathrm{O}$ método não apenas fornece um passe-partout, como incita a só se enxergar na riqueza dos temas de reflexão uma forma única, 
sempre parecida, com a condição de fazer-lhe certas correções elementares: um pouco como uma música que se reduzisse a uma única melodia, desde que compreendamos que esta se lê ora em clave de sol ora em clave de fá. Desse ponto de vista, o ensino filosófico exercitava a inteligência ao mesmo tempo em que ressecava o espírito". (op. cit., p. 49-50, grifo nosso)

A extensão do excerto transcrito justifica-se por se aproximar de algumas ideias expostas no debate sobre o ensino na universidade que então começava aqui em São Paulo. A importância da dissertação e da arguição oral puderam ser observadas ao longo deste estudo como marcas da tradição que foram impressas nas práticas universitárias paulistas. No rodapé do Boletim de 1937, da Cadeira de Sociologia, ao apresentar as notas de aproveitamento de seus alunos, Arbousse Bastide acrescenta o seguinte: "Os outros alunos, não tendo entregue trabalhos, terão suas notas de aproveitamento dadas após uma interrogação oral. Todos os estudantes que não figuram aí, não me entregaram trabalho e não se apresentaram para a interrogação oral, achando-se assim muito prejudicados por um zero. Se ainda houver tempo, precisam vir me encontrar para uma interrogação oral" (tradução nossa). O exame oral, além de verificar se o aluno conhecia o conteúdo ministrado no curso, ainda verificava outros elementos de sua formação, como a destreza com as palavras, a riqueza no que tange ao uso do vocabulário, a clareza ao se expressar. Se pensarmos que a missão estava incumbida de dar alma francesa à universidade brasileira, imprimindo um modo de lidar com o conhecimento que deveria ser perpetuado ao longo do desenvolvimento desta instituição, então era preciso que os professores franceses formassem segundo seus moldes aqueles que lhes sucederiam nas Cadeiras. A arguição deixava todos expostos, de modo que não apenas o conteúdo da disciplina ministrada pudesse ser apresentado, mas também o que aqueles alunos poderiam vir a ser, uma vez que o capital cultural apresentado pelos alunos paulistas estava aquém do esperado pelos professores da missão.

No documento intitulado "Remarques sur les conditions et l'organisation de l'enseignement de la sociologie à la Faculté de Philosophie, Sciences et Lettres de São Paulo (Brésil)" - sem data - escrito por Arbousse Bastide alguns dos obstáculos enfrentados para a realização do ensino são evidenciados. $\mathrm{O}$ acesso aos livros era considerado como um dos mais graves e urgentes problemas, o que fazia com que os professores mimeografassem textos para distribuir aos estudantes. Os franceses alegavam que não seria possível incutir hábitos de trabalho nos alunos se eles não tinham livros disponíveis. No Anuário da Faculdade de Filosofia, Ciências e Letras - 1937/1938, ao tratar da cooperação da França, o documento registra que "além de fornecer ilustres professores para as cátedras da USP, a França doou 120.000 francos em livros, que chegariam pelo porto de Santos". No que tange ao "método de ensino", o professor alega que para efetivar a missão de criar uma tradição universitária na FFCL, os estudantes precisariam ser "guiados de perto". Os seminários dados pelos docentes são apresentados como algo intermediário entre as aulas e as conversas, há o seguinte no documento referente a tal prática: "esse trabalho de seminário, como se diz na Alemanha, intermediário entre a aula e a conversação, me parece muito fecundo e apreciado pelos estudantes. É evidente que seria preciso, ainda, experimentar para criar um modo de ensino mais adaptado às circunstâncias, ao meio e às necessidades" (tradução nossa).

Com relação aos trabalhos realizados pelos alunos, vale a pena transcrever o seguinte trecho do documento: « Os trabalho dos estudantes de sociologia podem ser de diferentes tipos : 1) estudos de documentação social concretos (enquete, reunião de material de informação social), 2) uma dissertação sobre temas mais abstratos e propriamente sociológicos (questões de metodologia, conclusão a tirar de uma observação de fatos sociais), 3) análise crítica de uma obra de sociologia ou uma explicação sobre um conjunto de estudos sobre um autor, sobre uma escola sociológica, 4) (...), 5) explicação escrita ou oral de textos de filosofia social, de 
metodologia social ou de filosofia geral, 6) exposição oral de um tema relevante da sociologia ou de alguma ciência auxiliar e suas relações com a sociologia. É preciso admitir que não chegamos ainda a resultados muito satisfatórios, (...) mas é preciso reconhecer que se os estudantes mostram algum gosto pela análise oral dos fatos sociais diferentes que os cercam, eles se mostram ainda pouco aptos a todo trabalho que exija um esforço de composição, de discussão e de síntese » (p. 13 - tradução nossa). Nessa descrição, a dissertação e a exposição oral são valorizadas enquanto atividades realizadas pelos alunos e que também serviam à avaliação feita pelos professores.

No período inicial de funcionamento da FFCL, as turmas eram pequenas e os alunos de diferentes cursos poderiam assistir às aulas e aos seminários juntos, cursando disciplinas em comum, assim como os professores não atuavam junto a um único curso, mas lecionavam em vários deles. Em entrevista concedida a Didier Eribon, Claude Lévi-Strauss dizia que a universidade recém-criada, que era composta por "algumas dúzias" de estudantes, ficava "no centro da cidade, em velhos prédios, nos quais ainda se respirava uma atmosfera colonial. Enquanto que hoje a universidade, atingida como outras pelo gigantismo, está instalada em construções estilo Jussieu ou Nanterre, num imenso descampado" (LEVVI-STRAUSS, C.; ERIBON, D., 2005, p. 34).

Dos exames à promoção: a atribuição de critérios para a avaliação dos universitários

Os anuários são volumes produzidos pela universidade para publicar documentos e pesquisas produzidos no âmbito da instituição. Em estudo sobre a Escola Politécnica da USP, encontramos o trabalho de Bruno Bontempi Junior (2013) que se utilizou dos Anuários, dentre outras fontes. No Anuário da Faculdade de Filosofia, Ciências e Letras - 1937/1938, Roger Bastide defendia que houvesse uma ligação entre os diferentes cursos de modo que os estudantes não tivessem uma "impressão de ensino separado", travava-se da "colaboração de todos numa mesma obra de educação intelectual" (p. 14). Arbousse Bastide, enquanto chefe da missão, relatou ainda ao Ministère des Affaires Etrangéres, no documento acima citado, o que considerou ser o problema mais urgente encontrado com relação à clientela escolar paulista: a formação pré-universitária e a orientação pós-universitária dos estudantes. Ele dizia :

Se é relativamente fácil ver o que é preciso fazer num futuro mais ou menos distante, é talvez mais urgente indicar as dificuldades mais próximas e os pontos sobre os quais se deve fazer os primeiros esforços. Parece que eles devem ser aplicados a dois pontos bem precisos : 1) formar os futuros estudantes a fim de que o ensino recebido na FFCL possa ser fecundo sem que seja necessário para isso baixar o seu nível ; 2) prever situações verdadeiramente interessantes para aqueles estudantes que chegarem com sucesso ao fim de seus estudos superiores, em termos mais precisos : a FFCL não pode se desenvolver normalmente : 1) a não ser que o ensino secundário seja radicalmente reformado, 2) a não ser que a situação dos professores secundários seja moral e materialmente revalorizada. Sem dúvida nós devemos trabalhar para formar as elites, mas os candidatos à nobreza intelectual só apresentarão um esforço persistente e perseverante se a sociedade em que eles vivem lhes reservar uma função social verdadeiramente digna desse nome. Os estudantes que nos chegam, apesar de sua boa vontade, de sua inteligência e de seu trabalho, não possuem e não chegam a possuir rapidamente os instrumentos de cultura que deveria ser oferecida a eles pelo ensino secundário. Na falta de uma reformulação imediata do ensino secundário, poder-se-ia prever a organização de um ano propedêutico do ensino superior para todos os estudantes que não tivessem satisfeito verdadeiramente as boas condições do exame 
vestibular, cujos programas foram publicados recentemente. Assim, se poderia ser verdadeiramente exigente para os candidatos sem, contudo, eliminar pura e simplesmente aqueles que se revelem insuficientes, mas merecedores. Seria difícil dizer como a eficácia da cultura sociológica, sem falar da formação dos estudantes chamados a recebê-la e, em consequência sem dizer uma palavra dos esforços necessários para preparar o meio no qual ela deverá, pouco a pouco, fincar as suas raízes e dar frutos (página 14 - tradução nossa, grifos nossos).

Pierre Bourdieu² e Monique de Saint-Martin (1999), ao escreverem sobre "as categorias do juízo professoral", tratam das classificações que os professores produzem cotidianamente sobre os seus alunos. Ao estudar um conjunto de fichas individuais preenchidas por um professor de Filosofia que lecionava em um primeiro ano superior de Paris, os autores analisaram os adjetivos atribuídos aos estudantes em relação à sua origem social. Os estudantes provenientes das classes médias são objeto de julgamentos negativos, como bobo, servil, medíocre, vulgar, enquanto aqueles “(...) provenientes das frações da classe dominante mais rica em capital cultural escapam quase totalmente aos julgamentos negativos, mesmo eufemizados, assim como às virtudes pequeno-burguesas, e lhes são atribuídas com insistência as qualidades mais procuradas" (op. cit., p. 191). As virtudes escolares apreciadas na formação empreendida na FFCL, como o conhecimento dos autores e o domínio do vocabulário utilizado na área, a maneira de construir uma argumentação e demonstrá-la através dos trabalhos escritos correspondem a uma parte do objeto apresentado ao julgamento empreendido pelos professores, a outra, e bastante importante, diz respeito à exposição oral e a uma espécie de traquejo do qual deveriam ser portadores os candidatos à "nobreza intelectual". A esse propósito, vale a pena ainda lembrar as palavras de Bourdieu e Saint-Martin: "os critérios 'externos', mais frequentemente implícitos e mesmo recusados pela instituição, têm um peso ainda mais importante na apreciação das manifestações orais, posto que, aos critérios já mencionados, se junta tudo o que se relaciona com a palavra e, mais precisamente, o sotaque, a elocução e a dicção que são as marcas mais seguras, por serem as mais indeléveis, da origem social e geográfica, o estilo da linguagem falada, que pode diferir profundamente do estilo escrito, e enfim e principalmente a hexis corporal, as maneiras e a conduta, que são frequentemente designados muito diretamente nas apreciações" (op. cit., p. 192-193). A exposição oral era bastante valorizada na FFCL, na formação de seus alunos e também no Curso de Pedagogia, conforme é possível perceber já no Regulamento do Instituto de Educação (Decreto $n^{\circ} 7.067$, de 6 de abril de 1935), no qual é explicitado no artigo 76, que "em cada cadeira, terá o alumno, durante o semestre, duas notas, sendo uma de applicação e outra de exame, além de uma prova final” (p. 11). Não poderia ser promovido o aluno que tivesse faltado em $1 / 4$ dos trabalhos práticos ou das aulas teóricas em qualquer uma das cadeiras. A nota de aplicação consistia em assiduidade, chamada oral, exercícios práticos, trabalhos obrigatórios e espontâneos, e ainda "espírito de iniciativa". O exame consistia em uma prova sobre a matéria explicada no semestre. Cada disciplina possuía um tipo de trabalho prático diferente, quanto à bibliografia dos cursos, a maioria, era em inglês, francês e espanhol. Os trabalhos práticos poderiam consistir em atividades variadas, inquéritos e pesquisas, individuais e em grupos, ou ainda investigações sobre a escola primária. Monografias e seminários também eram práticas recorrentes nas aulas

\footnotetext{
${ }^{2}$ Recorrer à noção de "categorias do juízo professoral”, formulada por Pierre Bourdieu e Monique de SaintMartin, obedece ao investimento de compreender a história da educação em perspectiva sócio-histórica, tal como bem defende de modo geral Roger Chartier ao argumentar sobre a possibilidade de construção da história dos campos (espaços sociais) e do recurso aos conceitos sociológicos. Ver Chartier (2002) e também Catani (2008). Esta elaboração, é evidente, já estava presente nas interpretações de Émile Durkheim (2008).
} 
que serviam à avaliação das aprendizagens, conforme consta nos Programas para os cursos regulares e extraordinários para o ano de 1937 - FFCL/USP.

No Boletim de Exames Finais - 1947 - FFCL/USP, é possível conhecer a maneira como os professores chegavam à média final dos alunos. Os boletins não eram dos alunos, mas sim das Cadeiras, das disciplinas ministradas. Nestes documentos há o nome do aluno, seguido pela nota do exame escrito em uma coluna, a nota do exame oral em uma segunda coluna e a média final na terceira. A nota oral e a nota escrita tinham o mesmo peso e eram divididas por dois gerando a média final, por exemplo: $7+5=6$. Ao final destes boletins havia os nomes dos professores que compunham a banca examinadora destes exames, composta por três professores. Tais impressos eram datilografados e levavam o carimbo da FFCL da USP. A data destes boletins é de dezembro, normalmente a partir do dia 15. É comum encontrarmos nos Boletins publicados ao longo dos anos de 30 e 40, a seguinte inscrição no rodapé, como a que está no Boletim de 1938-39 - FFCL/USP: "artigo 133 - Cumpre ao professor atribuir semestralmente aos alunos uma 'nota de aproveitamento' nos trabalhos práticos e outros exercícios escolares da Cadeira. Esta nota será aplicada sob preparações, arguições, relatórios de trabalhos práticos e de excursões realizadas durante os respectivos períodos letivos e apresentados até o último dia de aula.

Parágrafo $1^{\circ}$ - O professor deverá enviar à Secretaria a relação das notas de aproveitamento dos alunos matriculados, até o último dia de aula do respectivo período letivo.

Parágrafo $2^{\circ}$ - Ao aluno que sonegar os elementos estabelecidos pelo professor para aplicação de notas de aproveitamento, a média geral de aprovação será calculada com o mesmo divisor 3 previsto no artigo 131.

Nos Boletins de Notas - Exame final - escrito/oral - 1944 - FFCL/USP, há a seguinte inscrição relativa ao exame oral final: "Aos... dias do mês de ... de $19 . .$. , perante a comissão examinadora de ..., compareceram os alunos abaixo mencionados, afim de prestarem prova oral final, nos termos do Regulamento. Depois de arguidas, receberam as notas que vão exaradas na coluna "nota oral final"'. Abaixo encontra-se um quadro com os nomes e as notas digitadas e preenchidas à mão: são quatro campos de notas, média de exames parciais, média de aproveitamento, nota de exame oral final, média geral. Ao final da página há os nomes e as assinaturas dos professores que compuseram a banca que julgou o exame oral final. Os Boletins de Notas Geral Noturno - 1954 - FFCL/USP, apresentam um formato diferente, trata-se de folhas impressas frente e verso na qual alguns dados são preenchidos à mão e datilografados. Por exemplo:

Universidade de São Paulo

Faculdade de Filosofia, Ciências e Letras

Boletim de Notas

Curso de ...

Cadeira de ...

Ano letivo de 19..

Período Noturno

Professor ...

Colunas: $\mathrm{n}^{\mathrm{o}}$, alunos, $1^{\mathrm{o}}$ aproveitamento, $1^{\mathrm{o}}$ parcial, exame $2^{\mathrm{a}}$ chamada, $2^{\circ}$ aproveitamento, $2^{\circ}$ parcial, média aproveitamento, média parcial, média geral. 
Todas as colunas eram preenchidas com as notas em formato numérico, exceto a última coluna (média geral) que poderia ser preenchida com: "oral", "repr." (em vermelho), "E. O.” (exame escrito e oral), ou notas altas, como 9,0 ou 9,37. Quando o aluno era repetente, estava marcado ao lado do nome dele "(repetente)", ou ainda "(transferido)" ou "adaptação". No rodapé da página está impresso o artigo 133. E no verso da página há campos para nome e assinatura do professor e data. São três campos: " 1 aproveitamento e $1^{\mathrm{a}}$ prova parcial", " $2^{\mathrm{a}}$ chamada" " $2^{\mathrm{o}}$ aproveitamento e $2^{\mathrm{a}}$ prova parcial” e abaixo "Observações:...". Para a realização dos exames de $2^{\mathrm{a}}$ época, era necessário realizar inscrição, conforme é possível verificar de acordo com o edital de 1943:

Edital de inscrição para os exames de $2^{\mathrm{a}}$ época

De ordem do Sr. Diretor faço público que estarão abertas de 11 a 15 de fevereiro corrente, as inscrições para os exames de $2^{\mathrm{a}}$ época em todos os cursos da Faculdade de Filosofia, Ciências e Letras.

Secretaria da Faculdade de Filosofia, Ciências e Letras da Universidade de São Paulo,

3 de fevereiro de 1942.

Secção de editais - publicar de 4 a 15 do corrente.

Para realizar o exame de $2^{\mathrm{a}}$ época, os alunos deveriam pagar uma taxa. Os exames de $2^{\mathrm{a}}$ época costumavam ser realizados no mês de fevereiro do ano seguinte àquele no qual ocorreu o curso, especialmente na $2^{a}$ quinzena do mês. Para julgar o desempenho dos alunos, havia uma banca julgadora formada por três professores. No estudo dos boletins publicados neste período, foi possível perceber que o tipo de exame aplicado nestas situações variava de acordo com a disciplina. Por exemplo: no ano de 1942, o exame de Sociologia era composto de prova oral enquanto o exame de Fundamentos Biológicos da Educação era composto de prova oral em um dia e prova escrita em outro. No Boletim de Notas de $2^{a}$ época e Exame Vago1950 - FFCL/USP, há uma uniformização com relação aos exames de $2^{\mathrm{a}}$ época em todas as disciplinas, sendo compostos por uma nota de prova oral mais uma nota de prova escrita, que somadas e divididas por dois davam origem à média.

\section{O exame vago}

Os exames vagos eram aplicados segundo a Lei $n^{\circ} 1.029$, de 30 de dezembro de 1949, que determinava que "os alunos matriculados em cursos superiores, que, em virtude de faltas de frequência legal às aulas teóricas de uma ou mais disciplinas, não puderam ser promovidos por média, nem inscrever-se para os exames finais, serão admitidos a exames de segunda época, na segunda quinzena de Fevereiro do ano seguinte, desde que tenham sido frequentes às aulas e exercícios práticos, obrigatórios, constantes do regulamento ou regimento da escola. Parágrafo único. Os exames de segunda época de cada disciplina, que versarão sobre toda a matéria do programa, constarão de prova escrita e oral, e, quando o regulamento ou regimento exigir, também de prova prática." Nestes exames os alunos eram submetidos à arguição de toda a matéria e não apenas do ponto sorteado. No Boletim de Notas de $2^{a}$ época - Exame Vago D. $e N$. $1952-F F C L / U S P$, é possível localizar os seguintes registros digitados em todas as folhas com letras vermelhas: "Nota: O aluno que não constar desta relação, não poderá prestar exame, salvo com autorização por escrito desta secretaria. De acordo com a lei dos exames vagos, (exames completos), abrangem toda a matéria quer dada ou não". Acrescido ao disposto na lei $\mathrm{n}^{\mathrm{o}} 1.029$, no qual determinou que os estudantes deveriam ser submetidos ao exame de toda a matéria do programa, o registro no boletim de 1952 da FFCL determinava que o exame abrangeria toda a matéria, mesmo que não tivesse sido dada. 
Em 1947, dois anos antes da lei que instituiu o exame vago ter sido promulgada, Jorge Americano, que foi reitor da USP entre 1941 e 1946, publicou um texto intitulado $A$ universidade de São Paulo: Dados, problemas e planos, no qual tratou das notas parciais e dos exames finais. Ele ponderava: "Um fato absolutamente estranho e inconcebível em país civilizado costuma verificar-se periodicamente no Brasil: a alteração arbitrária, pelo governo, das notas de julgamento de provas parciais ou finais. Todo professor adota um critério de julgamento de provas, segundo o qual cada prova é considerada péssima, má, sofrível, regular, boa, ótima. Dada alguma dúvida no julgamento, o professor procurará no caso uma solução intermediária: entre má e sofrível, entre regular e boa, etc. Traduzindo esse critério, que pode dizer-se universal, em escala numérica de 0 a 10 teremos: 0=péssima, 2=má, 4=sofrível, 6=regular, 8=boa, 10=ótima. Os números ímpares servirão, no caso, para traduzir as modalidades intermediárias. É evidente que qualquer escala numérica, 0-100, 0-25, etc, pode servir à tradução aritmética, de vez que o julgador equipare a nota péssima a zero e nota ótima ao valor máximo da escala. Salientamos estes detalhes para fazer sentir que determinado julgamento é sempre expresso numericamente em função de uma tabela prefixada, onde cada conceito - péssimo, regular, ótimo - equivale a um número. Ora, se, posteriormente ao julgamento proferido com base em certa expressão numérica, surge uma lei ou decreto que altera a correspondência entre a expressão numérica e o julgamento, isto é, se uma lei toma o número 4, expressão do julgamento - sofrível - e declara que esse número, que quando foi lançado exprimia reprovação, passa a exprimir aprovação, tal lei é criminosa, por contrafazer o julgamento efetivo. Entretanto, isso é o que periodicamente acontece no Brasil: estudantes reprovados representam ao poder público pedindo que altere os julgamentos proferidos; o poder público à cata de popularidade declara então por lei ou decreto que as notas proferidas reprovando valem aprovação; e os professores cujo julgamento foi criminosamente adulterado guardam silêncio, esperando que no futuro as coisas se passem diferentemente. Uma reação faz-se necessária" (p. 167-168). Dois anos depois foi instituído o exame, escrito e oral, que versava sobre toda a matéria do programa, o exame vago.

No Guia da Faculdade de Filosofia, Ciências e Letras da Universidade de São Paulo, de 1951, é possível conhecer o regime de promoção vigente na instituição naquela época, no qual o exame oral continua presente:

\section{A- Primeira época}

1-Considerando-se a cadeira isoladamente

O atual regime de promoção, em vigor na Faculdade, é o seguinte:

a) $\mathrm{O}$ aluno que obtiver média igual ou superior a 4 de aproveitamento, e igual ou superior a 7 , nas provas parciais, será considerado aprovado, independente de exame final.

b) $\mathrm{O}$ aluno que obtiver média igual ou superior a 4 de aproveitamento e, nas provas parciais, média entre 5 e 6,99, deverá prestar somente exame oral final. A média geral 5, exigida para aprovação, será extraída dos seguintes elementos: - nota do exame oral final, média de aproveitamento e média das provas parciais.

c) $\mathrm{O}$ aluno que obtiver média igual ou superior a 4 de aproveitamento e média entre 3 e 4,99, nas provas parciais, deverá prestar exames finais (escrito e oral). A média geral 5, exigida para aprovação, será extraída dos seguintes elementos: - média dos exames finais (escrito e oral), média de aproveitamento e média das provas parciais" (p. 91-92).

B-2 época

$\mathrm{O}$ aluno que obtiver média inferior a 4 de aproveitamento, deverá prestar exame de $2^{\mathrm{a}}$ época, qualquer que seja a média nas provas parciais. 
A média geral 5, exigida na aprovação, será extraída da nota da prova escrita e da prova oral e, quando o regimento ou regulamento, exigir, nota da prova prática.

No Anuário da Faculdade de Filosofia, Ciências e Letras da Universidade de São Paulo1952, no qual consta uma descrição das atividades desenvolvidas pelas cadeiras e departamentos, há a seguinte informação acerca do curso de Didática Geral, ministrado pelo professor Onofre de Arruda Penteado Junior, no Curso de Pedagogia ${ }^{3}$ : "os trabalhos para nota de aproveitamento foram exclusivamente orais, tendo a cadeira suprimido todo e qualquer trabalho escrito, desde que tem como finalidade a formação de professores. Por esse motivo, vários temas foram propostos pelo professor e desenvolvidos oralmente pelos alunos" (p. 219). No mesmo documento há outra referência acerca da influência que a missão francesa deixava nos modos de ensinar da universidade: "considerando que os cursos monográficos instituídos na secção de Filosofia pelos professores franceses e conservados até o presente como uma espécie de tradição, pois inegavelmente são os que mais se prestam a um desenvolvimento de nível universitário, apresentam, contudo, a desvantagem de não oferecerem aos alunos uma visão de conjunto da História da Filosofia, resolveu-se organizar para os próximos anos, a título de experiência, um programa de compreendesse os principais aspectos da Filosofia ocidental, até o século XVIII, e que deverá ser realizado em dois anos, ou mesmo mais, se for necessário. Isso, sem prejuízo dos cursos monográficos, dos quais cada turma deverá seguir pelo menos um, no conjunto de seus estudos. Resolveu-se ainda, de acordo com os professores respectivos, dar aos alunos de Ciências Sociais e de Pedagogia, cursos diferentes e de acordo com suas necessidades próprias" (p. 247-248).

\section{O concurso de habilitação}

O exame oral também estava presente na seleção que era feita para os candidatos ingressarem nos cursos, o que hoje é conhecido como vestibular, em 1943 recebia o nome de "concurso de habilitação" (Guia da Faculdade de Filosofia, Ciências e Letras da Universidade de São Paulo - 1943), segundo o documento "as provas do concurso de habilitação são em número de duas para cada disciplina que consta do programa para o referido concurso. A primeira prova é um exame vago escrito e a segunda uma arguição oral" (p. 43). De acordo com o Guia da Faculdade de Filosofia, Ciências e Letras da Universidade de São Paulo - 1965, "os programas para o concurso de habilitação versarão exclusivamente sobre matérias dos programas do ciclo colegial, constando de provas escritas e orais das seguintes matérias, conforme o curso a que se destina o candidato: (...) 14- Curso de Pedagogia - provas escritas e orais das seguintes disciplinas: História Geral, Português, Francês ou Inglês" (p. 97-98). Para a realização da matrícula era necessário que o estudante apresentasse um "atestado recente de idoneidade moral" (p. 93). Até o início dos anos de 1960, poucas pessoas se submetiam ao exame para ingresso na universidade, então é compreensível que fosse possível a realização do exame oral para selecionar os candidatos. Em 1962, por exemplo, o Curso de Pedagogia teve 155 candidatos, dos quais 33 foram aprovados, não preenchendo as 60 vagas disponíveis para o primeiro ano (Estatísticas da Faculdade de Filosofia, Ciências e Letras da Universidade de São Paulo - 1934-1967).

No Guia Filosofia e Educação - Faculdade de Filosofia, Ciências e Letras da Universidade de São Paulo - 1966, já é possível encontrar o termo vestibular no exame de admissão à universidade: "os exames vestibulares para o curso de Pedagogia compreendem provas escritas e orais de Português e História Geral e orais de uma língua viva (Francês ou Inglês). Os professores do departamento consideram o sistema vigente até agora, bastante

\footnotetext{
3 Sobre a posição da Pedagogia no mundo científico e as disciplinas de base na formação de seus
} profissionais, ver Borges; Gatti Jr, 2013. 
insatisfatório. O problema dos exames vestibulares para todos os cursos da Faculdade continua em estudo, pois pretende-se corrigir, futuramente, as falhas principais do atual sistema" (p. 59).

\section{As práticas de avaliação nos programas das disciplinas}

Os programas da FFCL de 1934 a 1968 foram examinados com o objetivo de localizarmos referências sobre a avaliação em cada um dos cursos, no entanto, além de cada curso apresentar a sua disciplina do programa de um jeito muito diferente um do outro, poucos trataram das práticas de avaliação realizadas. Nos Programas para os cursos regulares e extraordinários para o ano de 1953 - FFCL/USP, por exemplo, não há muita referência à avaliação da aprendizagem, somente na Cadeira de Sociologia II há os temas para as pesquisas e os trabalhos que deveriam ser desenvolvidos. Na disciplina de Psicologia da Aprendizagem é dito que haveria o planejamento e a elaboração de uma pesquisa sobre o fenômeno da aprendizagem. Uma exceção pode ser identificada nos Programas para 1968 aprovados pela congregação - FFCL/USP, onde é possível encontrar uma descrição dos trabalhos realizados pelos alunos na disciplina "Higiene", ministrada no curso de Pedagogia: "3. Os assuntos de discussão de cada aula são fornecidos no início do curso, com bibliografia a ser estudada antes de cada aula, para uma prova escrita sobre o tema estudado, para então serem debatidos. (...) 5 . O curso é semestral com carga de 4 horas semanais. A Nota de aproveitamento (N. A.) resulta da média entre as notas de atividades práticas (N. Pr.) e teórica (N. Te.). A N. Pr. Será atribuída aos projetos individuais e coletivos, que devem ser apresentados em seminário. A N. Te. será dada de acordo com os resultados das 'provinhas' semanais e da prova final”. (p. 145) Nos Programas para 1959 aprovados pela Congregação - FFCL/USP é possível conhecer alguns elementos quanto às avaliações praticadas em algumas disciplinas do Curso de Pedagogia. Em Filosofia da Educação e em Didática Especial de Matemática, de Línguas e de História os alunos deveriam apresentar seminários. Em Didática Especial de Química e de História Natural, no âmbito da verificação do aprendizado, os estudantes deveriam elaborar trabalhos teóricos e práticos e realizar exames, sabatinas e testes. Em Teoria Geral da Educação, seriam realizados seminários e trabalhos de aproveitamento. Entre os termos utilizados para referir-se à avaliação encontramos: verificação do aprendizado, verificação e avaliação do aprendizado e trabalho de aproveitamento. No ano seguinte, nos Programas aprovados pela Congregação para $o$ ano letivo de 1960 - FFCL/USP foi possível conhecer as seguintes práticas de avaliação empreendidas pelos professores: em Psicologia Educacional, os alunos faziam experimentos, pesquisas e redigiam relatórios; em Administração Escolar e Educação Comparada eram realizados seminários e em Teoria Geral da Educação, eram feitos trabalhos de aproveitamento e seminários. No ano de 1966, nos Programas para 1966 aprovados pela congregação - FFCLUSP, na disciplina "Didática: Metodologia do Ensino Médio", encontramos o seguinte: "6 - Verificação e avaliação do aprendizado: a) as provas 'tradicionais'; b) os testes; c) outras modalidades de verificação" (p. 203). Em outras modalidades de verificação, seminários, exames orais e sabatinas poderiam ser realizados. A palavra "testes" passa a ser utilizada em alguns programas nesta época.

Na Estrutura normativa da Universidade de São Paulo (Decreto $n^{\circ} 52.326$, de 16 de dezembro de 1969 - D. O. de 17-12-69), documento que contém o Estatuto e as Portarias que implantaram a Reforma Universitária, o capítulo IV diz respeito ao "Conselho de Ensino, Pesquisa e Extensão de Serviços à Comunidade", entre suas atribuições estão as seguintes: "V- indicar às congregações normas de avaliação de ensino e de promoção dos alunos; (...) IX - deliberar quanto à forma de ingresso de candidatos aos currículos de graduação; (...) X - conceituar e uniformizar os critérios referentes às "unidades de crédito"” (p. 18). O documento referente à implantação da Reforma Universitária diz ainda que caberia ao departamento organizar o trabalho docente e discente. A informação se repete no Regimento Geral da Universidade de São Paulo - 1972, no qual é dito que ao Conselho de Ensino, Pesquisa e Extensão de Serviços à Comunidade compete indicar às Congregações normas de avaliação de ensino e promoção de alunos. 
Em 1970, a Portaria $n^{\circ} 1.024$, de 15 de janeiro de 1970 (D. O. de 20-1-70), que Fixa normas de caráter transitório para implantar a reforma universitária, determinou que a aferição de mérito e os exames obedecerão aos regimentos de cada unidade. Com relação ao desempenho nos alunos e à sua participação na gestão da universidade, a Portaria $n^{o} 1.449$, de 14 de abril de 1971. (D. O. de 15-4-71), que Consolida disposições sobre a eleição dos representantes do corpo discente junto ao Conselho Universitário, definiu que nenhum representante pode ter nota menor do que 6 (seis).

\section{As práticas de avaliação das aprendizagens: entre o $\operatorname{artesanal}^{4} \mathrm{e} o$ institucional}

Ao longo deste estudo foi possível perceber que as práticas de avaliação das aprendizagens nas primeiras décadas de criação do Curso de Pedagogia eram realizadas em um processo muito artesanal. Na Faculdade de Filosofia, Ciências e Letras as turmas eram pequenas e as pessoas se conheciam. Ao realizarem o concurso de habilitação entre os candidatos, por exemplo, o contato que era propiciado pelo exame oral poderia permitir que os professores captassem muito mais as potencialidades desses alunos, aquilo que eles poderiam "vir a ser", do que aquilo que eles de fato traziam, pois o capital cultural apresentado era baixo segundo os padrões exigidos pelos que vieram fundar a universidade e pelos seus herdeiros intelectuais. Como foi dito anteriormente, em 1962, por exemplo, o Curso de Pedagogia teve 155 candidatos, dos quais 33 foram aprovados, não preenchendo as 60 vagas disponíveis para o primeiro ano (Estatísticas da Faculdade de Filosofia, Ciências e Letras da Universidade de São Paulo - 1934-1967).

Com a Reforma Universitária (Lei $n^{\circ}$. 5.540, de 1968) e a elaboração dos novos Estatutos da Universidade de São Paulo, em 16 de dezembro de 1969, foi criada a Faculdade de Educação que passou a funcionar efetivamente como tal a partir de $1^{\circ}$ de janeiro de 1970 . A realização dos grandes vestibulares, como se sabe, tornou a hipótese dos exames orais uma quase impossibilidade. A preservação das provas de redação, nesses casos, busca garantir a valorização do uso feito da linguagem, do vocabulário, da argumentação e da clareza na exposição das ideias. Marcadas pela influência exercida pelos professores que chegaram com a missão francesa, as práticas de avaliação e de ensino empregadas desde as primeiras décadas de funcionamento do Curso de Pedagogia evidenciavam a concepção de uma formação humanista valorizada pelo exercício da oralidade e da dissertação.

\section{Referências}

BONTEMPI JR, Bruno. "As sessões solenes da Faculdade de Filosofia: rituais da comunidade intelectual uspiana”. Estudos Ibero-Americanos, v.34, 2008, p.168-187. https://doi.org/10.15448/1980-864X.2008.2.4510

BONTEMPI JR, Bruno. O país, a ciência e o engenheiro nos Anuários da Escola Politécnica de São Paulo (1900- 1947), CBHE, 2013. (Apresentação de Trabalho/Comunicação).

BORGES, B. G.; GATTI JR, Décio. O lugar da Pedagogia no mundo científico e o papel das disciplinas de base. Inter-ação (UFG. Impresso), v.38, p.573-592, 2013. https://doi.org/10.5216/ia.v38i3.20826

BOURDIEU, Pierre; SAINT-MARTIN, Monique de. "As categorias do juízo professoral" In.: CATANI, A.; NOGUEIRA, M. A. (Orgs.) Escritos de educação. Rio de Janeiro: Vozes, 1999, p. $185-216$.

\footnotetext{
${ }^{4}$ Em conversa com o professor Celso de Rui Beisiegel acerca das práticas de avaliação das aprendizagens realizadas na universidade pela geração dos "herdeiros" da missão francesa, surgiu a expressão "artesanal" associada aos modos de trabalho dos docentes.
} 
CATANI, Denice. "Pierre Bourdieu e a História (da Educação)" In: FARIA FILHO, L. M. (org.) Pensadores sociais e a história da educação. $2^{\mathrm{a}}$ ed. - Belo Horizonte: Autêntica Editora, 2008 , p. $319-340$.

CARDOSO, Irene de Arruda Ribeiro. A universidade da comunhão paulista: o projeto de criação da Universidade de São Paulo São Paulo: Cortez/Autores Associados, 1982.

CHARTIER, R.; LOPES, J. L. "Pierre Bourdieu e a História" (debate), Toppoi. Rio de Janeiro; março 2002, p.139-182. https://doi.org/10.1590/2237-101X003004005

CUNHA, Luiz Antonio. A Universidade Reformada - O Golpe de 1964 e a Modernização do Ensino Superior. Rio de Janeiro: Francisco Alves, 1988.

CUNHA, Luiz Antonio. A Universidade Crítica - O Ensino Superior na República Populista. Rio de Janeiro: Francisco Alves, 1983.

CUNHA, Luiz Antonio. A Universidade Temporã - O Ensino Superior da Colônia à Era de Vargas. Rio de Janeiro: Francisco Alves, 1980.

DURKHEIM, E. As regras do método sociológico. São Paulo: Martin Claret, 2008.

FÁVERO, Maria de Lourdes. Universidade do Brasil: das origens à construção. Rio de Janeiro: Editora UFRJ, 2010.

FÁVERO, Maria de Lourdes. Universidade e Poder: Análise Crítica/fundamentos históricos: 1930-45. Brasília-DF: Plano, 2000.

FÉTIZON, Beatriz Alexandrina de Moura. "Subsídios para o estudo da Universidade de São Paulo", tese de doutorado, FEUSP, 1986.

LEVI-STRAUSS, Claude. Tristes trópicos São Paulo: Companhia das Letras, 1998.

LEVI-STRAUSS, Claude; ERIBON, Didier. De perto e de longe. São Paulo: Cosac Naify, 2005.

Note pour monsieur Marx - Service des Oeuvres Françaises à l'Étranger, Ministère des Affaires Etrangéres.

Notes sur une mission à la Faculté nouvelle de São Paulo (juin-décembre 1934) - Service des Oeuvres Françaises à l'Étranger, Ministère des Affaires Etrangéres.

PERRENOUD, Philippe. Práticas pedagógicas, profissão docente e formação: perspectivas sociológicas Lisboa: Dom Quixote, 1993.

Remarques sur les conditions et l'organisation de l'enseignement de la sociologie à la Faculté de Philosophie, Sciences et Lettres de São Paulo (Brésil) - (sem data) - P. Arbousse Bastide (chefe da missão francesa em São Paulo) - Service des Oeuvres Françaises à l'Étranger, Ministère des Affaires Etrangéres.

São Paulo. Decreto n ${ }^{\circ} 6.283$ de 25 de janeiro de 1934. Crea a universidade de São Paulo e dá outras providências.

São Paulo. Decreto no 39 de 3 de setembro de 1934. Aprova os estatutos da Universidade de São Paulo

USP. AMERICANO, Jorge. A universidade de São Paulo: Dados, problemas e planos, 1947.

USP. Anuário da Faculdade de Filosofia, Ciências e Letras - 1937/1938 - FFCL/USP

USP. Anuário da Faculdade de Filosofia, Ciências e Letras da Universidade de São Paulo1952 (publicado em 1954) - FFCL/USP

USP. Boletim de 1937 - Secção do Expediente - FFCL/USP 
USP. Boletim de 1938-39 - Secção do Expediente - FFCL/USP

USP. Boletim de Exames Finais - 1947 - FFCL/USP

USP. Boletins de Notas - Exame final-escrito/oral - 1944 - FFCL/USP

USP. Boletins de Notas Geral Noturno - 1954 - FFCL/USP

USP. Boletim de Notas de $2^{a}$ época e Exame Vago1950 - FFCL/USP

USP. Boletim de Notas de $2^{a}$ época - Exame Vago D. e N. - 1952 - FFCL/USP

USP. Estatísticas da Faculdade de Filosofia, Ciências e Letras da Universidade de São Paulo - 1934-1967 - FFCL/USP

USP. Estrutura normativa da Universidade de São Paulo (Estatuto e Portarias que implantaram a reforma universitária) Decreto $n^{\circ} 52.326$, de 16 de dezembro de $1969-D$. O. de 17-12-69 - USP

USP. Guia da Faculdade de Filosofia, Ciências e Letras da Universidade de São Paulo - 1951FFCL/USP

USP. Guia da Faculdade de Filosofia, Ciências e Letras da Universidade de São Paulo - 1943 $-F F C L / U S P$.

USP. Guia da Faculdade de Filosofia, Ciências e Letras da Universidade de São Paulo - 1965 $-F F C L / U S P$.

USP. Guia Filosofia e Educação - Faculdade de Filosofia, Ciências e Letras da Universidade de São Paulo - 1966 - FFCL/USP.

USP. Lei $n^{o} 1.029$, de 30 de dezembro de 1949, Dispõe sobre exames de $2^{a}$ época - Secção do Expediente - FFCL/USP

USP. Portaria GR n ${ }^{\circ}$ 174, de 21 de julho de 1965 - Altera dispositivos dos Estatutos da Universidade de São Paulo e dá outras providências - FFCL/USP

USP. Portaria $n^{\circ}$ 1.024, de 15 de janeiro de 1970 (D. O. de 20-1-70) Fixa normas de caráter transitório para implantar a reforma universitária - USP

USP. Portaria no 1.449, de 14 de abril de 1971. (D. O. de 15-4-71) Consolida disposições sobre a eleição dos representantes do corpo discente junto ao Conselho Universitário - USP

USP. Programas para os cursos regulares e extraordinários para o ano de 1937 -_FFCL/USP

USP. Programas para os cursos regulares e extraordinários para o ano de 1953 - FFCL/USP

USP. Programas para 1959 aprovados pela congregação - FFCL/USP

USP. Programas para 1960 aprovados pela Congregação - FFCL/USP

USP. Programas para 1966 aprovados pela Congregação - FFCL/USP

USP. Programas para 1968 aprovados pela Congregação - FFCL/USP

USP. Estatuto da Universidade de São Paulo - Ante-projeto aprovado pelo Conselho Universitário em sessão de 16 de janeiro de 1939 - USP/Empresa Gráfica da “Revista dos Tribunais” 1939. 